\title{
Pax-5 Inhibits Breast Cancer Proliferation Through MiR-215 Up-regulation
}

\author{
NICOLAS LEBLANC ${ }^{1,2}$, JASON HARQUAIL ${ }^{1,2}$, NICOLAS CRAPOULET ${ }^{1,2}$, \\ RODNEY J. OUELLETTE ${ }^{1,2}$ and GILLES A. ROBICHAUD ${ }^{1,2}$ \\ ${ }^{1}$ Department of Chemistry and Biochemistry, University of Moncton, Moncton, Canada; \\ ${ }^{2}$ Atlantic Cancer Research Institute, Moncton, Canada
}

\begin{abstract}
Background/Aim: In breast cancer, Pax-5 promotes pro-epithelial features and suppresses malignant cancer processes. However, the molecular mechanism of this antitumor activity remains largely unknown. This study aimed to identify the cellular roles of Pax-5-regulated miRNAs in breast cancer progression. Materials and Methods: After transient transfection of Pax-5 in MDA-MB-231 breast cancer cells, Pax5-regulated miRNA expression was examined by nextgeneration sequencing. The identified Pax-5-regulated miRNAs were then validated by $q R T-P C R$ and examined for the roles they play in breast cancer cells. Results: Pax-5 was shown to be an effective modulator of miR-215-5p and its target genes. MiR-215 inhibited cell proliferation and migration of breast cancer cells, but not cell invasion. More importantly, Pax-5induced suppression of cancer cell proliferation and migration was found to be miR-215-dependent. Interestingly, miR-215 profiling in clinical tumor samples showed that miR-215 expression was lower in cancer tissues in comparison to healthy controls. Conclusion: Pax-5 reduces breast cancer proliferation and migration through up-regulation of the tumor suppressor miR-215. This result supports the use of miR-215 as a prognostic marker for breast cancer.
\end{abstract}

Breast cancer is the most common malignancy among women and the leading cause of cancer-related deaths worldwide (1). A better understanding of the molecular mechanisms supporting breast cancer development and progression are needed to identify novel therapeutic targets and to develop targeted treatments for breast cancer patients. Emerging evidence has recently revealed that Pax-5 is an

This article is freely accessible online.

Correspondence to: Gilles A. Robichaud, Université de Moncton, Moncton, NB, E1A 3E9, Canada. Tel: +1 5068584320, Fax: +1 5068584541, e-mail: gilles.robichaud@umoncton.ca

Key Words: Pax-5, breast cancer, miRNA, miR-215-5p, EMT/MET. imperative molecular regulator of several cancers, including B cell, lung and breast cancer (2-4). Pax-5 is a member of the Paired Box (Pax) transcription factor family which plays a crucial and indispensable role in various developmental processes $(5,6)$. Pax-5 is normally expressed in the developing brain and in all stages of B cell development except in terminally differentiated plasma cells $(7,8)$. Given the requirement of Pax5 expression to maintain B-cell lineage (9), numerous studies have shown that Pax- 5 acts as a potent oncogene in many types of lymphoma and lymphocytic leukemia (10-12). In opposition to its oncogenic effects in B-cell cancers, Pax-5 has been shown to confer tumor suppressive properties in carcinomas $(2,13,14)$. Intriguingly, Pax-5 supresses cell proliferation and can modulate epithelial-mesenchymal/mesenchymal-epithelial (EMT/MET) transitioning in breast cancer cells $(15,16)$. Furthermore, we and others have shown that Pax-5 expression reduces colony formation and migratory capabilities by inducing epithelial characteristics in invasive breast carcinoma cells $(2,15,17)$. These reports illustrate the critical role of Pax-5 in breast cancer. However, there is still a paucity of information on the molecular basis underlying its biology.

Non-coding RNAs such as microRNAs (miRNAs) have emerged as important regulators of gene expression in numerous biological processes and are involved in many diseases including cancer $(18,19)$. MiRNAs are approximately 22 nucleotides in lengths and regulate gene expression at the post-transcriptional level by binding to a complementary (usually the 3'UTR) region of its target mRNAs, subsequently leading to translational inhibition and/or mRNA degradation (20). MiRNAs can have oncogenic or tumor suppressor properties in cancer and are often found aberrantly expressed in many types of cancer $(21,22)$. Moreover, miRNAs play important roles in cellular processes closely related to cancer aggressiveness such as cell proliferation, invasiveness and motility $(23,24)$. Recent studies have demonstrated that miRNAs are regulated by transcription factors. Accordingly, aberrant transcription factor expression can lead to miRNA dysregulation, thus contributing to breast cancer malignancy (25). These include the transcription factors p53, MYC, and ZEB2 (25-27). 
In the present study, we demonstrate that Pax-5 regulates numerous microRNAs including miR-215 in aggressive breast carcinoma cells. We also show that Pax-5 consequently modulates downstream targets of miR-215. More importantly, we establish that miR-215 is a potent inhibitor of cell proliferation and migration, two processes tightly related to cancer aggressiveness. Together, our findings elucidate a non-coding RNA downstream signaling network of Pax-5. These findings are essential for a comprehensive understanding of breast carcinogenesis.

\section{Materials and Methods}

Cell lines and cell culture conditions. The human mammary cell line MDA-MB-231 (MB231) (mammary ductal carcinoma, HTB-26) was obtained from the American Type Culture Collection (ATCC, Manassas, VA, USA). MB231 cells were maintained in Dulbecco's modified Eagle's medium (DMEM) supplemented with 10\% FBS, L-glutamine $(2 \mathrm{mM})$, penicillin (100 units $/ \mathrm{ml})$, and streptomycin $(100 \mu \mathrm{g} / \mathrm{ml})$. Cell culture media and reagents were obtained from Thermo Fisher Scientific (Burlington, ON, Canada) except for the FBS which was provided by PAA Laboratories (Etobicoke, ON, Canada).

Plasmids and transfections. Transient transfections of Pax-5 were conducted using either the empty pcDNA3.1 vector; or, a vector encoding the Pax -5 mRNA as previously described (10). Briefly, MB231 cells were seeded into six-well plates $\left(5 \times 10^{5}\right.$ cells/well) and incubated overnight. Cells were then transfected with $2 \mu \mathrm{g}$ of plasmid DNA using the the X-tremeGENE 9 reagent (Roche, Brandord, CT, USA) according to the manufacturer's protocol. Stable MB231 cell lines expressing recombinant Pax-5 or empty pcDNA3.1 vector were generated by treating cells 24 h-posttransfection with $500 \mu \mathrm{g} / \mathrm{ml}$ geneticin (Thermo Fisher). Cells were then selected for antibiotic resistance, expanded and characterized for recombinant Pax-5 expression.

Gene modulation experiments were performed using either a siRNA pool against Pax-5 transcripts (ON-TARGET plus, Dharmacon, Lafayette, CA, USA), a miR-215-5p inhibitor (AntimiR miRNA inhibitor, Thermo Fisher) or a miR-215-5p mimic (mirVana miRNA mimic, Thermo Fisher). Cells were seeded in sixwell plates $\left(5 \times 10^{5}\right.$ cells/well $)$ and transiently transfected with $50 \mathrm{nM}$ of siRNA, $36 \mathrm{nM}$ of miRNA mimic, or $36 \mathrm{nM}$ of miRNA inhibitor by using Lipofectamine 2000 reagent (Thermo Fisher) in OptiMEM according to the manufacturer's recommended protocol. Control cells were transfected with a non-specific (non-targeting) siRNA (Dharmacon), scrambled non-targeting miRNA mimic (mirVana miRNA Mimic Negative Control, Thermo Fisher) or scrambled non-targeting miRNA inhibitor (Anti-miR miRNA Inhibitor Negative control, Thermo Fisher) respectively.

RNA extraction and real-time PCR. Total RNA including miRNAs was extracted using the mirVana miRNA isolation kit (Thermo Fisher) according to the manufacturer's protocol. Reverse transcription of mRNA from $1 \mu \mathrm{g}$ of total RNA was performed using oligo-dT and SuperScript III reverse transcriptase (Thermo Fisher). Gene expression was measured with the SYBR Green 2X FastMix for iQ (Quanta, Biosciences Inc, Beverly, MA, USA). For miRNA analysis, $100 \mathrm{ng}$ of RNA was converted to complementary DNA
(cDNA) using the Taqman microRNA Reverse Transcription Kit (Thermo Fisher). MiR-215-5p, miRNA-532-5p, miRNA-3619-5p, miRNA-489-3p, and miRNA-130a-3p expressions were measured with the miRNA-specific TaqMan assay (Thermo Fisher) on a CFX Connect Real-Time PCR Detection System (BioRad, Mississauga, ON, Canada). Primer sequences are listed in Table I. Relative differences in expression were determined by using the $\Delta \Delta \mathrm{Ct}$ of Livak and Schmittgen, 2001 (28) method using HPRT and RNU48 as the endogenous standard for mRNA and miRNA respectively.

Cell viability assays. Cellular viability was monitored using the CellTiter-Blue assay (Promega, Madison, WI, USA) as previously described (29). After transfection, cells were seeded in 96 well plates $\left(3 \times 10^{3}\right.$ cells/well) where $20 \mu \mathrm{l}$ of CellTiter-Blue substrate was added up to $100 \mu \mathrm{l} /$ well and incubated for $1 \mathrm{~h}$ at $37^{\circ} \mathrm{C}$. Afterwards, microplates were subjected to fluorescence analysis on a SpectraMax I3 fluorescence plate reader (Molecular Devices, Sunnyvale, CA, USA) at $560_{\mathrm{Ex}} / 590_{\mathrm{Em}}$. Cell viability was measured daily on a time period of 4 days.

Western blot analysis. Cells were lysed in whole cell lysate buffer (0.125 M Tris pH 6.8, glycerol $0.2 \mathrm{~g} / \mathrm{ml}, 4.0 \% \mathrm{SDS}, 10 \mathrm{mg} / \mathrm{ml}$ PMSF, $5 \mu$ protease inhibitor cocktail set III (Calbiochem, Etobicoke, Canada) and $100 \mathrm{mM}$ sodium orthovanadate (Sigma, Oakville, Canada)). The total protein concentration for each sample was determined using the Pierce BCA protein assay kit (Thermo Fisher). Twenty micrograms of total protein from each sample was subjected to SDS-PAGE and transferred onto a polyvinylidene difluoride (PVDF) membrane. The membranes were blocked with $5 \%$ non-fat dry milk and incubated overnight at $4{ }^{\circ} \mathrm{C}$ with anti-Pax5 (exon 5/6, New England Peptide, Gardner, MA, USA) or antiG3PDH (\#2275-PC-100, Trevigen, Gaithersburg, MD, USA) followed by incubation with the corresponding HPR-conjugated secondary antibodies. Immunoblots were visualized using SuperSignal Chemiluminescent Substrates (Thermo Fisher) and ChemiDoc Imaging system (Bio-Rad).

Cell migration and invasion assays. Migration and invasion assays were performed as previously described (30). Briefly, cells were starved in $200 \mu \mathrm{l}$ DMEM containing $0.1 \%$ FBS for $16 \mathrm{~h}$ and then placed in transwell inserts $\left(5 \times 10^{4}\right.$ cells/insert) (Greiner Bio-One, Monroe, NC, USA). Following an incubation at $37^{\circ} \mathrm{C}$ for $1 \mathrm{~h}$ in DMEM $0.1 \%$ FBS, the transwell inserts were transferred into wells containing DMEM $20 \%$ and incubated for $16 \mathrm{~h}$ at $37^{\circ} \mathrm{C}$. Inserts containing DMEM $0.1 \%$ were used as negative controls. After incubation, migrated cells on the lower surface were harvested with trypsin and submitted to a cell viability assay using CellTiter-Blue as described above. For invasion essays, inserts were pre-coated with $100 \mu \mathrm{l}$ of Matrigel (BD Biosciences, San Jose, CA, USA) in DMEM $0.1 \%$ and incubated overnight.

Next Generation Sequencing (NGS). RNA library construction and sequencing were conducted following Ion Torrent (Thermo Fisher) protocols. Small RNAs were loaded on an Ion PI Chip v2 and sequenced with an Ion Proton Sequencer using the 260 flows parameter. Small RNA libraries were constructed from three biological replicates for each condition. Initial FASTQ files were gathered and adaptor sequences were trimmed. Sequencing data filtered by eliminating reads of $<16$ and of $>60$ nucleotides. Reads with bases showing Q scores of $<20$ were eliminated. 
Table I. Primer sequences.

\begin{tabular}{lcc}
\hline & Forward primers $\left(5^{\prime} \rightarrow 3^{\prime}\right)$ & Reverse primers $\left(5^{\prime} \rightarrow 3^{\prime}\right)$ \\
\hline HPRT & TGA CAC TGG CAA AAC AAT GCA & GGT CCT TTT CAC CAG CAA GCT \\
Pax-5 & GCG CAA GAG AGA CGA AGG T & CTG CTG CTG TGT GAA CAA GTC \\
ALCAM & AAG TTG GGT GAC TGC ATT TC & ATT ATG ACC ACC GCT CCT TC \\
CTNNBIP1 & CCT ATG CAG GGG TGG TCA AC & CGA CC GGA AAA CGC CAT CA \\
DICER 1 & AGC CCC AGC CCA GCG ATG AA & GTC CAG GAT TGG GGC CAA GAG TCC \\
DYRK3 & CTC AGC ACT TTT TGG ATG GAG G & TTG GGT GCC TTG GAT GAA CTG \\
EFNB2 & ACC AGT CCT TGT CCA GGT AGA A & TGG GGT GTT TTG ATG GTT TT \\
EREG & GTG ATT CCA TCA TGT ATC CCA GG & GCC ATT CAT GTC AGA GCT ACA CT \\
FNDC3B & CCC TCC CTA TCT GAC TCA CCA & GGT CCG GTA ACA GGT GGG TA \\
\hline
\end{tabular}

Statistical analyses. Student's $t$-test was used to analyse the significance of the differences. All data are presented as the mean \pm standard error. A two-sided $p$-value $<0.05$ was regarded as significant.

\section{Results}

Pax-5-regulated miRNA profiling in breast carcinoma. To understand the effects of Pax-5 on miRNA expression profiles in breast carcinoma cells, we sequenced small RNA in MB231 cells overexpressing Pax-5 with an Ion Torrent next-generation sequencer. These Pax-5 overexpressing MB231 cells, when compared to empty vector (pcDNA3.1) transfected control cells, revealed a list of 41 statistically significant deregulated miRNAs following fold change and abundance exclusions (Figure 1A). MiRNAs with $\geq 0.3 \log _{2}$ fold change between samples and an average expression greater than 1.00 were retained. In order to select clinically significant miRNAs, regulated by Pax-5 in breast cancer tissues, we analyzed the expression levels of Pax5 and the 41 miRNAs of interest using the breast cancer miRNA and mRNA sequencing dataset of The Cancer Genome Atlas (TCGA) (http://cancergenome.nih.gov). A cohort of 113 breast cancer patients was divided into subgroups characterized with either high $(\geq 1.5)$ or low $(\leq 0.67)$ Pax-5 expression levels and evaluated the corresponding average and median miRNA expression (Table II). In accordance with the NGS results, average and median expression of miR-215 and miR-532 were increased; whereas, miR-3619, miR-489, and miR-130a average and median expression levels were decreased in Pax-5-high expression tumors versus Pax-5-low expression tumors (Figure $1 \mathrm{~B}$ and $\mathrm{C})$. These findings are in agreement with our NGS results which suggest a role for the Pax-5 transcription factor as a modulator of miRNA expression profiles in breast cancer cells.

Validation of Pax-5-modulated miRNAs. In order to validate the modulation of the selected five miRNAs by Pax-5, qRTPCR in MB231 cells transiently transfected with the Pax-5 recombinant gene was performed (Figure 2A). First, we made use of Western blots to confirm recombinant expression of
Pax-5 in the MB231 cells. miR-215, miR-532, and miR-489 relative miRNA expression was $3.01,1.70$, and 0.31 times higher, respectively, in Pax-5-bearing cells compared to empty vector-transfected control cells, in accordance to NGS and TCGA results. MiR-130a and miR-3619 also showed differential levels although not significant when compared to control cells. To further validate the role of Pax-5 in the modulation of miR-215, -532, and -489 , MB231 stably expressing either Pax-5 or pcDNA empty vector were transfected with a silencing siRNA pool targeting Pax -5 to reverse these effects. As expected, siRNA suppression of Pax5 was minimal in MB231-pcDNA control cells given the low endogenous Pax-5 levels in these cells (15). On the other hand, Pax-5 mRNA levels in Pax-5 transfected cells were reduced by $92 \%$ following siPax -5 transfection in comparison to control cells treated with a non-specific siRNA (nontargeting siRNA control) (Figure 2B). Of the three miRNAs validated in Figure 2A (i.e. miR-215, -532 and -489), only the expression of miR-215 was rescued following Pax-5 inhibition in the MB231 breast cancer cell line (Figure 2C). Our results indicated that miR-215 is tightly regulated by Pax-5, and for this reason, investigation of the function of miR-215 in breast cancer cells was performed.

Identification of miR-215 targets. Reports have shown that elevated levels of miR-215 are associated with better prognostic and clinical outcomes for breast cancer patients $(31,32)$. However, the mechanistic role of miR-215 in breast cancer remains to be elucidated. Thus, four different algorithms that predict miRNA targets to uncover the downstream signaling targets of miR-215: DIANNA (http://diana.imis .athena-innovation.gr/DianaTools/), TargetScan (http://www.targetscan.org/vert_71/), RNAhybrid (https://bibiserv.cebitec.uni-bielefeld.de/rnahybrid), and microRNA.org (http://www.microrna.org/microrna/home.do) were used. This prediction approach indicated 439 miRNA common targets (Figure 3A). Then the DAVID functional annotation tool was used for a functional analysis of this list 

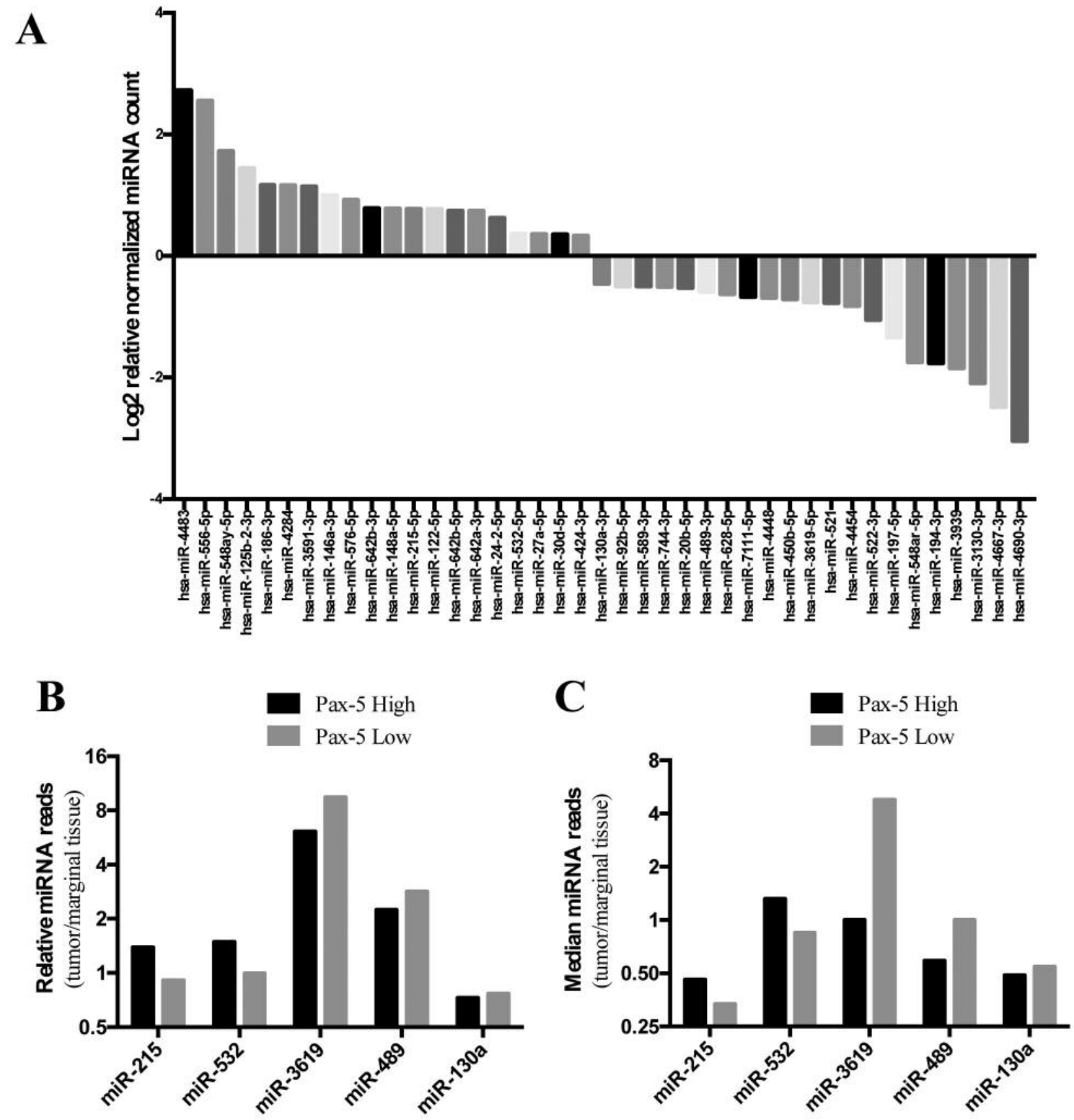

Figure 1. Pax-5 miRNA profiling in breast carcinoma cells and tissues. (A) MB231 cells were transfected with either recombinant Pax-5 or the empty vector (pcDNA3.1) and $48 \mathrm{~h}$ later were submitted to Ion Torrent Next-Generation Sequencing. Data are represented as differential miRNA expression between Pax-5 and pcDNA3.1-transfected cells of three biological experiments $(p<0.05)$. Average $(B)$ and median $(C)$ expression of miR-215-5p, miR-532-5p, miR-3619-5p, miR-489-3p, and miR-130a-3p in TCGA patients presenting a 1.5-fold upregulation (Pax-5 high) or downregulation of Pax-5 (Pax-5 low) in tumours are shown as a fold change of the tumor relative to the marginal healthy tissue.

of the 439 predicted miR-215-targeted genes (33). Intriguingly, several of the top categories in the KEGG pathway analysis were found to be associated with known and reported Pax-5 breast cancer processes (Figure 3B and
Table III). Among these pathways in cancer, regulation of actin cytoskeleton and MAPK signaling pathways were the most enriched. Then, genes that were highlighted in this analysis were selected to assess whether miR-215 could 
Table II. TCGA data dividing a cohort of 113 breast cancer patients into subgroups characterized with either high ( $\geq 1.5)$ or low ( $\leq 0.67)$ Pax-5 expression levels and the corresponding average and median miRNA expression profiles.

\begin{tabular}{|c|c|c|c|c|c|}
\hline miRNA & $\begin{array}{c}\text { NGS } \log 2 \text { relative } \\
\text { miRNA } \\
\text { count }\end{array}$ & $\begin{array}{l}\text { AVG Exp. in Pax-5 } \\
\text { Up-regulated } \\
\text { tumors }\end{array}$ & $\begin{array}{l}\text { AVG Exp. in Pax-5 } \\
\text { Down-regulated } \\
\text { tumors }\end{array}$ & $\begin{array}{l}\text { MEDIAN Exp. in Pax-5 } \\
\text { Up-regulated } \\
\text { tumors }\end{array}$ & $\begin{array}{l}\text { MEDIAN Exp. in Pax-5 } \\
\text { Down-regulated } \\
\text { tumors }\end{array}$ \\
\hline hsa-miR-4690-3p & -3.042 & N/A & N/A & N/A & N/A \\
\hline hsa-miR-4667-3p & -2.485 & N/A & N/A & N/A & N/A \\
\hline hsa-miR-3130-3p & -2.093 & 1.326 & 1.447 & 0.946 & 0.748 \\
\hline hsa-miR-3939 & -1.848 & N/A & N/A & N/A & N/A \\
\hline hsa-miR-194-3p & -1.763 & 1.604 & 1.231 & 1.344 & 1.116 \\
\hline hsa-miR-548ar-5p & -1.746 & N/A & N/A & N/A & N/A \\
\hline hsa-miR-197-5p & -1.337 & 1.223 & 1.174 & 0.974 & 0.809 \\
\hline hsa-miR-522-3p & -1.050 & 4.633 & 10.042 & 1.000 & 1.000 \\
\hline hsa-miR-4454 & -0.822 & N/A & N/A & N/A & N/A \\
\hline hsa-miR-521 & -0.773 & 1.660 & 2.872 & 1.000 & 1.000 \\
\hline hsa-miR-3619-5p & -0.760 & 6.112 & 9.478 & 1.000 & 4.793 \\
\hline hsa-miR-450b-5p & -0.711 & 2.603 & 2.443 & 2.063 & 1.484 \\
\hline hsa-miR-4448 & -0.690 & N/A & N/A & N/A & N/A \\
\hline hsa-miR-7111-5p & -0.673 & N/A & N/A & N/A & N/A \\
\hline hsa-miR-628-5p & -0.630 & 2.700 & 2.658 & 2.326 & 1.870 \\
\hline hsa-miR-489-3p & -0.585 & 2.241 & 2.832 & 0.588 & 1.000 \\
\hline hsa-miR-20b-5p & -0.522 & 4.797 & 3.815 & 2.788 & 1.450 \\
\hline hsa-miR-744-3p & -0.508 & 1.422 & 1.956 & 1.323 & 1.194 \\
\hline hsa-miR-589-3p & -0.502 & 1.814 & 1.327 & 1.515 & 1.114 \\
\hline hsa-miR-92b-5p & -0.500 & 3.513 & 3.495 & 2.782 & 2.192 \\
\hline hsa-miR-130a-3p & -0.458 & 0.728 & 0.767 & 0.488 & 0.544 \\
\hline hsa-miR-424-3p & 0.332 & 2.716 & 2.868 & 1.733 & 1.612 \\
\hline hsa-miR-30d-5p & 0.356 & 0.840 & 1.214 & 0.715 & 0.769 \\
\hline hsa-miR-27a-5p & 0.359 & 1.312 & 1.535 & 1.154 & 1.210 \\
\hline hsa-miR-532-5p & 0.367 & 1.487 & 0.997 & 1.316 & 0.848 \\
\hline hsa-miR-24-2-5p & 0.628 & 1.192 & 1.251 & 0.963 & 0.947 \\
\hline hsa-miR-642a-3p & 0.745 & 4.171 & 9.055 & 1.926 & 1.630 \\
\hline hsa-miR-642b-5p & 0.745 & 1.266 & 1.537 & 1.000 & 1.000 \\
\hline hsa-miR-122-5p & 0.773 & 1.215 & 1.491 & 1.000 & 1.000 \\
\hline hsa-miR-215-5p & 0.776 & 1.389 & 0.910 & 0.461 & 0.335 \\
\hline hsa-miR-148a-5p & 0.781 & 2.058 & 2.947 & 1.761 & 1.955 \\
\hline hsa-miR-642b-3p & 0.788 & 1.266 & 1.537 & 1.000 & 1.000 \\
\hline hsa-miR-576-5p & 0.925 & 1.828 & 2.062 & 1.416 & 1.212 \\
\hline hsa-miR-146a-3p & 0.997 & 2.146 & 1.125 & 1.517 & 0.791 \\
\hline hsa-miR-3591-3p & 1.145 & N/A & N/A & N/A & N/A \\
\hline hsa-miR-4284 & 1.165 & 1.000 & 1.107 & 1.000 & 1.000 \\
\hline hsa-miR-186-3p & 1.168 & 1.053 & 1.242 & 0.927 & 0.998 \\
\hline hsa-miR-125b-2-3p & 1.446 & 0.351 & 0.318 & 0.303 & 0.206 \\
\hline hsa-miR-548ay-5p & 1.727 & N/A & N/A & N/A & N/A \\
\hline hsa-miR-556-5p & 2.557 & 4.474 & 16.809 & 1.727 & 3.118 \\
\hline hsa-miR-4483 & 2.725 & N/A & N/A & N/A & N/A \\
\hline
\end{tabular}

modulate their expression. Thus, a breast cancer model of miR-215 overexpression through the transfection of miRNA215 mimics was developed that showed elevated miR-215 levels in a MB231 cells $24 \mathrm{~h}$ and $48 \mathrm{~h}$ post transfection (Figure 3C). Next, the mRNA levels of predicted miR-215 target genes was evaluated (i.e. ALCAM, CTNNBIP1, DICER1, DYRK3, EFNB2, EREG, FNDC3B, and ZEB2) using TaqMan PCR. As expected, all mRNA targets of miR215 were found to be decreased in miR-215 transfected cells when compared to transfected controls (Figure 3D). Given that Pax -5 is a positive regulator of miR-215, modulation of these miR-215 target genes by Pax-5 in MB231 cells was examined. Interestingly, all miR-215 targets (with the exception of EREG) were found to be downregulated in Pax5-transfected cells (Figure 3E), suggesting that these latter genes are modulated by Pax-5 via miR-215. Altogether, these results demonstrate that the Pax-5-miR-215 axis can modulate key molecular mediators of cancer biological processes. 
A
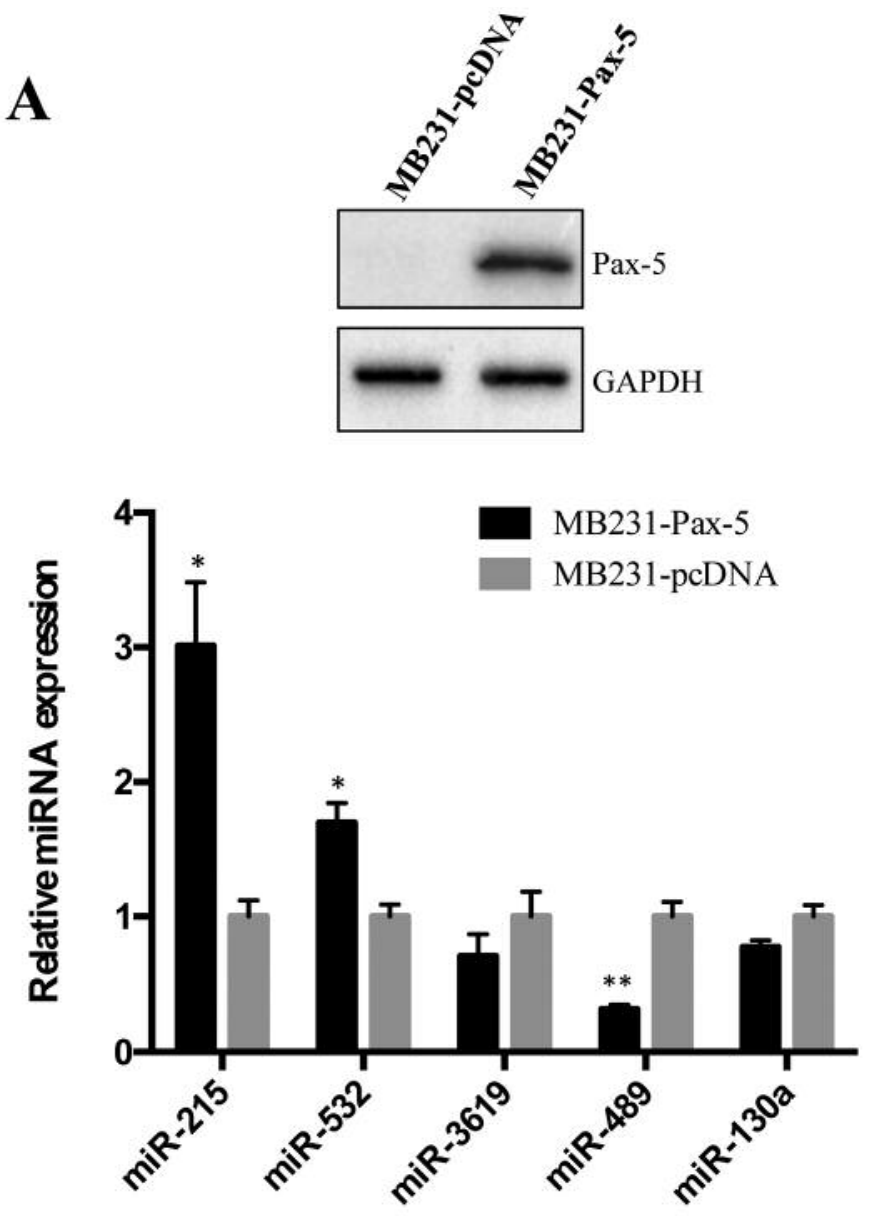

B

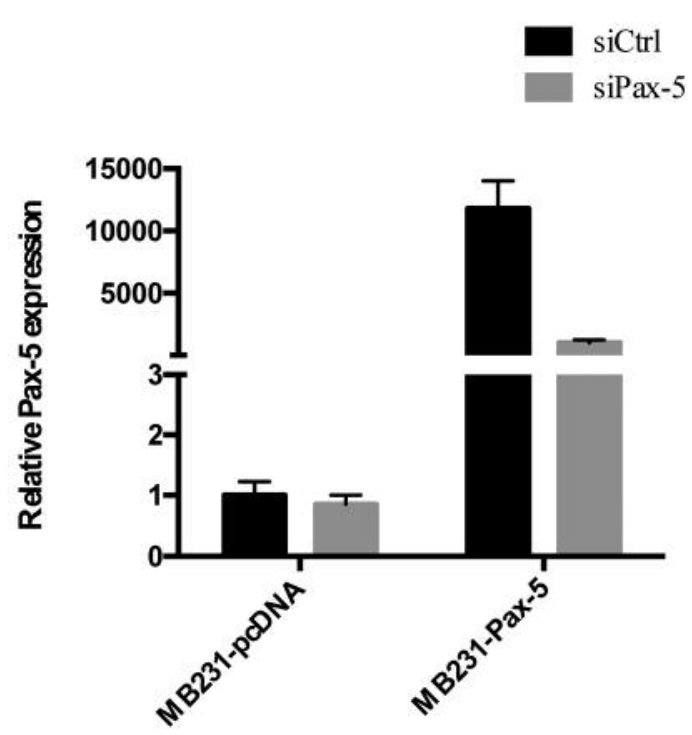

C

miRNA-215

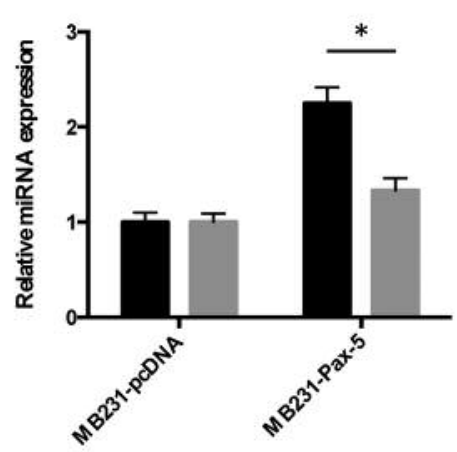

miRNA-532

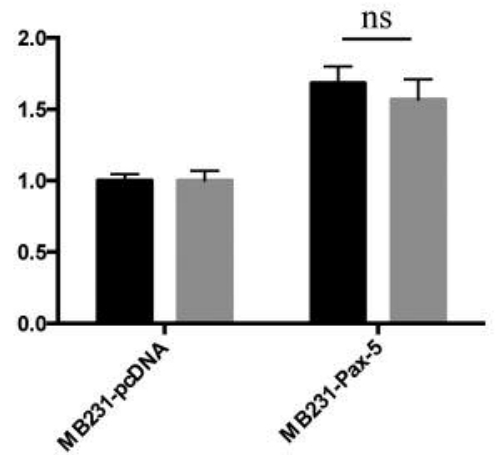

miRNA-489

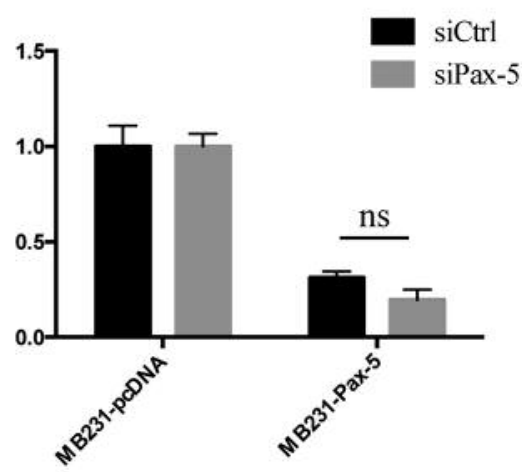

Figure 2. Validation of Pax-5-modulated miRNAs. (A) MB231 cells were transfected with either Pax-5 or pcDNA3.1 and evaluated for miR-215-5p, miR-532-5p, miR-3619-5p, miR-489-3p, and miR-130a-3p expression using RT-qPCR (lower panel). Western blots were also performed on Pax-5 and GAPDH on these treated cells (upper panel). (B) Pax-5 expression and (C) miR-215-5p, miR-532-5p, and miR-489-3p expression levels were also determined by RT-qPCR in MB231 cells transfected with a Pax-5 silencing siRNA (siPax-5) or a control scrambled siRNA (siCtrl) for 72 h. MiRNA and MRNA levels were normalized against the HPRT and the small-nucleolar RNA 48 (RNU48), respectively. Data are presented as means $\pm S E M$ of independent experimental triplicates $(* p<0.05, * * p<0.01$, ns: No significance). 
A
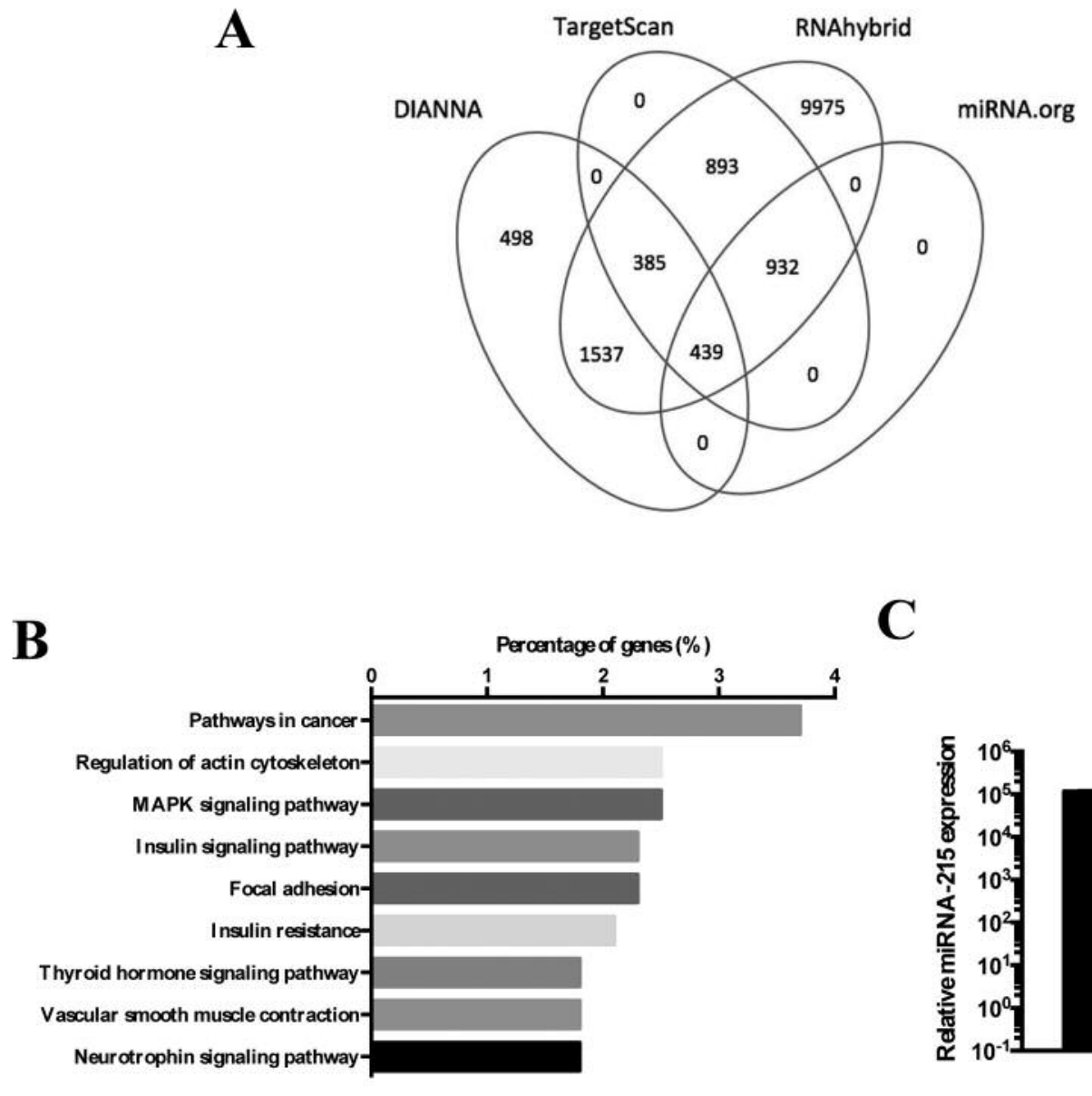

C

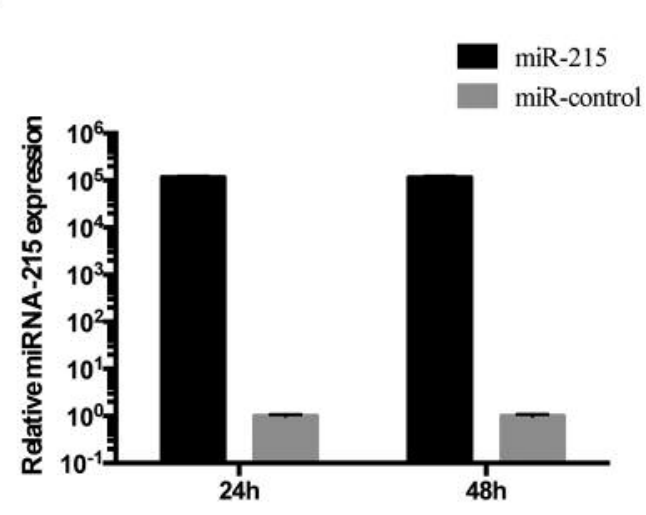

D

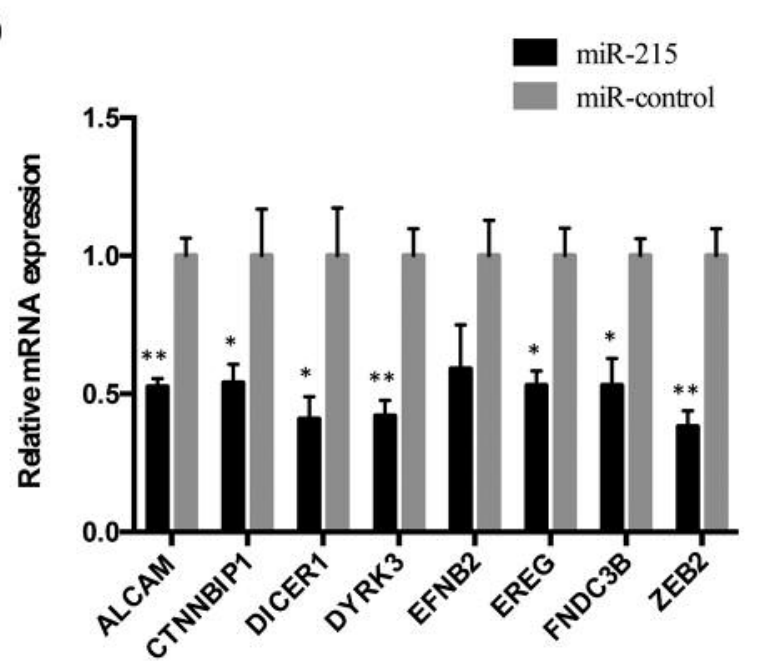

$\mathbf{E}$

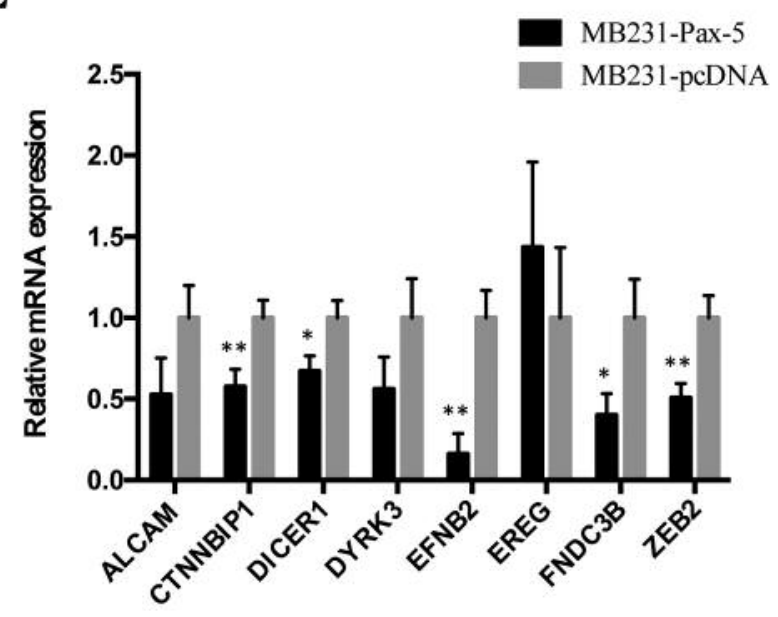

Figure 3. Identification of miR-215 targets. (A) The number and identification of predicted mRNA targets of miR-215 were determined by software tools (i.e. DIANNA, TargetScan, RNAhybrid, and miRNA.org). (B) Kyoto encyclopedia of genes and genomes (KEGG) pathway analysis of miR215 target genes was performed with DAVID bioinformatics. (C) MiR-215 and (D) miR-215 target genes expression was evaluated by qRT-PCR in MB231 cells transiently transfected with miR-215 mimic (miR-215) or scrambled non-targeting mimic (miR-control). (E) Transcriptional expression of miR-215 target genes was also monitored in MB231-Pax5 and MB231-pcDNA stable cell lines. MiRNA and mRNA expression levels were normalized against HPRT and RNU48, respectively. Data is presented as means \pm SEM of independent experimental triplicates $\left({ }^{*} p<0.05\right.$, $\left.* * p<0.01\right)$. 
miR-215 inhibits breast cancer cell proliferation. We have previously reported that Pax-5 inhibits breast cancer cell growth (15). Our findings herein also reveal that miR-215 is a modulator of genes implicated in cellular growth and proliferation (i.e. EFNB2, EREG, and FNDC3B). We thus investigated whether the modulation of miR-215 levels could result in changes in breast cancer cell proliferation. To study this, MB231 cells were transfected with miR-215 mimics and subsequently cell viability was measured over time using a colorimetric microplate assay. An inhibition of cell growth by $44 \%$ in miR-215-transfected cells at day 4 post-transfection in comparison to scramble transfected controls was observed (Figure 4A). To further determine the involvement of miR215 on Pax-5-mediated suppression of cell growth rescue assays on MB231-Pax-5 cells were performed by transfecting anti-miR-215. First, we confirmed that the transfection of anti-miR-215 resulted in the inhibition of miR-215 levels by at least 50\% in MB231 cells (Figure 4B). Next, as revealed in Figure $4 C$, we show that transient inhibition of miR-215 in MB231-Pax-5 cells rescued cell growth to the level of control cells. Together, these results indicate that the attenuation of breast cancer growth by Pax -5 is in partially mediated by the downstream effects of miR-215.

miR-215 suppresses cell migration. Given that Pax-5 has been shown to suppress breast cancer aggressive features (2, 15) the ability of miR-215 to modulate breast cancer malignant processes was explored (i.e. cell migration and invasion). To this direction, MB231 cells were transfected with miR-215 mimics and compared to cells treated with non-specific microRNA (scramble RNA). Elevated expression of miR-215 significantly decreased the migration capacity of MB231 cells by $69 \%$ when compared to miRcontrol cells (Figure 5A). To assess whether Pax-5 mediated suppression of breast cancer migration (2, 15) was attributable to miR-215, migration experiments on MB231 cells stably expressing Pax-5 and transfected anti-miR-215 were performed. As expected, MB231-Pax-5 cells migrated less than the control MB231-pcDNA cells by $46 \%$ (Figure $5 \mathrm{~B})$. More importantly, the reduction in migration capacity of MB231-Pax-5 cells was completely abolished by miR-215 silencing using anti-miR-215 transfection. Next, the role of miR-215 in regulating cell invasion was examined using matrigel-filled transwell inserts. MiR-215 did not influence invasive capacity of MB231 cells (Figure 5C). Collectively, these results demonstrate that miR-215 is a modulator of cell migration, an essential process in breast cancer progression. More importantly, miR-215 is a pivotal mediator of Pax-5induced suppression of breast cancer migration.

Clinical relevance of $\mathrm{miR}-215$ in breast cancer. To evaluate the clinical relevance of miR-215, the expression levels of miRNA in breast cancer tissues and non-tumorous breast
Table III. KEGG pathway analysis of the list of 439 predicted miR-215targeted genes.

\begin{tabular}{lcc}
\hline Term & Count & $\%$ \\
\hline Pathways in cancer & 16 & 3.7 \\
Regulation of actin cytoskeleton & 11 & 2.5 \\
MAPK signaling pathway & 11 & 2.5 \\
Insulin signaling pathway & 10 & 2.3 \\
Focal adhesion & 10 & 2.3 \\
Insulin resistance & 9 & 2.1 \\
Thyroid hormone signaling pathway & 8 & 1.8 \\
Vascular smooth muscle contraction & 8 & 1.8 \\
Neurotrophin signaling pathway & 8 & 1.8 \\
cGMP-PKG signaling pathway & 8 & 1.8 \\
Prostate cancer & 7 & 1.6 \\
Hepatitis B & 7 & 1.6 \\
Gap junction & 6 & 1.4 \\
Estrogen signaling pathway & 6 & 1.4 \\
Glucagon signaling pathway & 6 & 1.4 \\
Amphetamine addiction & 5 & 1.1 \\
Chronic myeloid leukemia & 5 & 1.1 \\
Aldosterone synthesis and secretion & 5 & 1.1 \\
Prion diseases & 4 & 0.9 \\
Endocrine and other factor-regulated calcium reabsorption & 4 & 0.9 \\
Cocaine addiction & 4 & 0.9 \\
\hline
\end{tabular}

All $p$-Values $<0.1$.

tissues of 100 breast cancer patients was analyzed using the available breast cancer dataset of The Cancer Genome Atlas (TCGA). When comparing miR-215 profiles in cancer tissues to healthy marginal samples, miR-215 levels were found to be deregulated in a total of $91 \%$ of all tumor samples. Specifically, miR-215 was downregulated in $70 \%$ of cases while was over-expressed in $21 \%$ of cases $( \pm 1.25$ fold difference between breast cancer tissue and healthy marginal tissue) (Figure 6A). More precisely, the expression of miR-215 is significantly lower in tumor samples, as compared with non-tumour tissue (Figure 6B). Our results suggest that miR-215 is clinically relevant in breast cancer tissues where its expression levels are apparently lower.

\section{Discussion}

Emerging evidence indicates that Pax -5 is a critical regulator of the multistep processes involved in breast cancer malignancy. Despite the importance of Pax-5 in breast carcinogenesis, the association between this transcription factor and downstream miRNA regulation remains largely unknown. In this study, miR-215-5p is identified as a tumor suppressive miRNA that is up-regulated by Pax-5 in breast cancer cells. Accordantly, it is demonstrated that miR-215 is under-expressed in clinical breast cancer tumor tissues.

In an attempt to identify the downstream miRNA expression profile of the Pax-5 transcription factor in malignant breast 

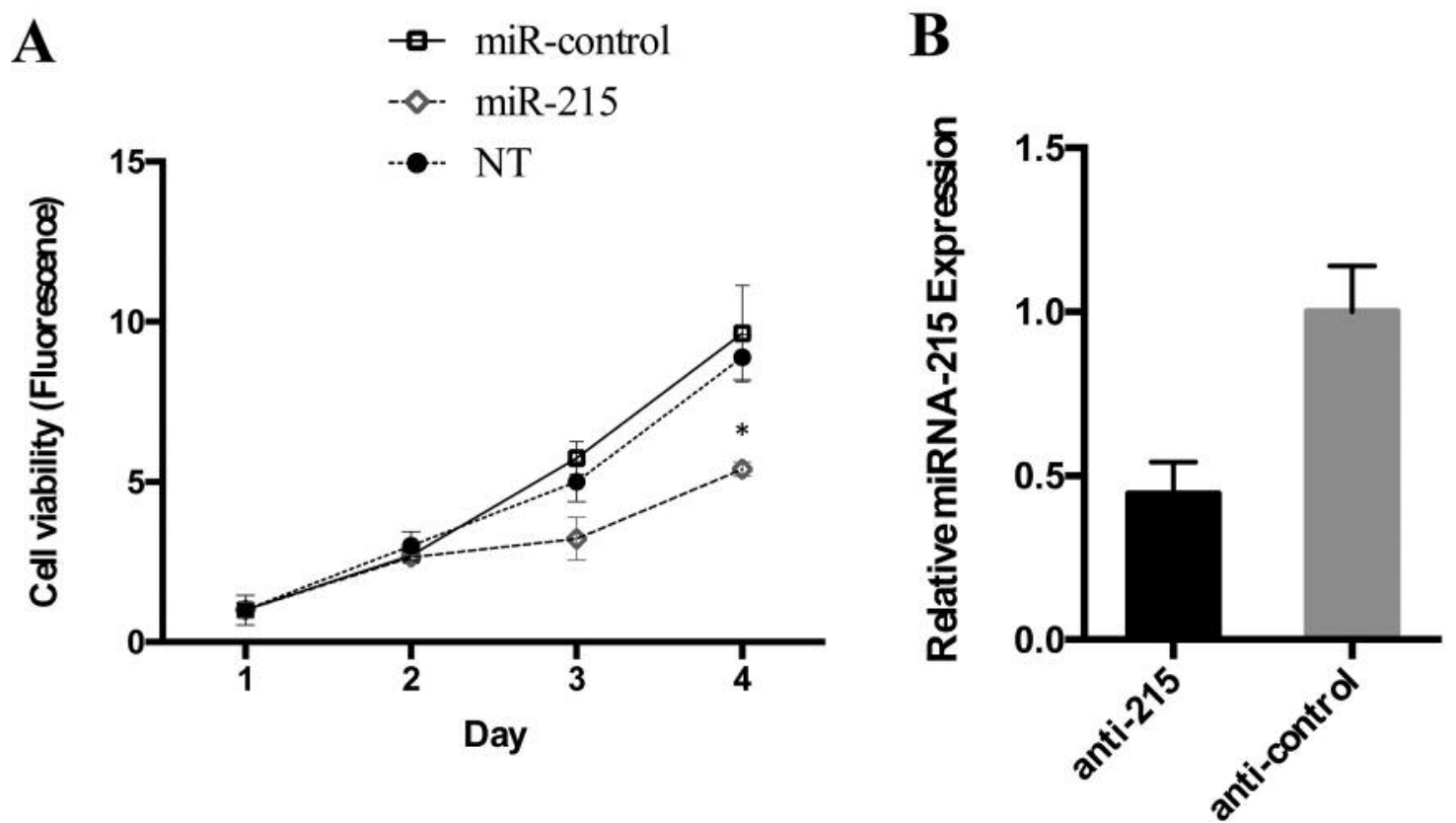

C

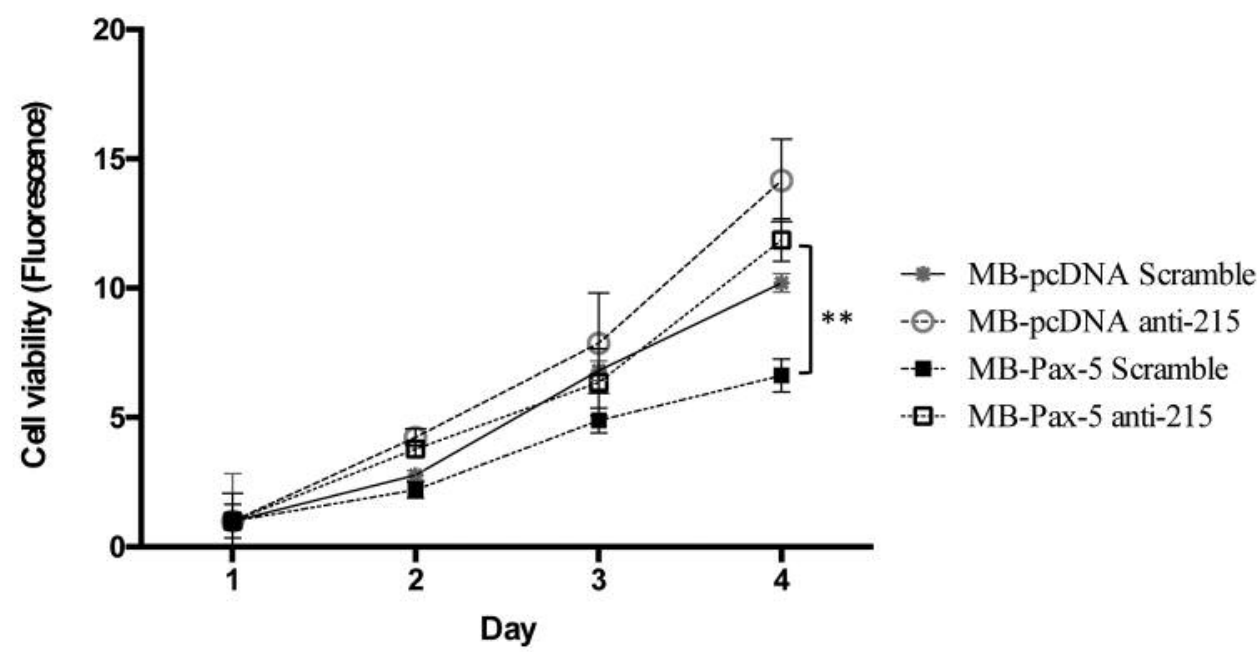

Figure 4. miR-215 inhibits cell proliferation. (A) MB231 cells transfected either with miR-215 mimics (miR-215), scrambled non-targeting mimic (miR-control) or non-transfected (NT) were monitored for cell viability over time (1 to 4 days) using the CellTiter-Blue viability assay. (B) MiR215 expression was evaluated by qRT-PCR in MB231 cells transfected with miR-215 inhibitors (anti-215) or scramble miRNA controls (anti-control) at $24 \mathrm{~h}$ and normalized against RNU48. (C) Cell viability assays were then performed in MB231-Pax-5 and MB231-pcDNA cells transfected with anti-miR-215 (anti-215) or scramble non-targeting inhibitor (anti-control). Data is presented as means \pm SEM of independent experimental triplicates $(* p<0.05, * * p<0.01)$.

cancer cells, microRNA sequencing on Pax-5-transfected MB231 breast cancer cells was performed. Our experiments identified 41 miRNAs significantly deregulated by Pax-5 expression when compared to vector-transfected controls. This study is the largest compilation of Pax-5-regulated miRNA expression profile in a breast cancer cell line. Of the 41 Pax5-regulated miRNAs, at least 5 were found to be correlated with Pax-5 expression levels in breast cancer clinical tissues. In validation, the use of a TCGA analysis and approach inherently assures a clinical relevance for the latter miRNAs through their respective aberrant expression profiles in clinical samples. Interestingly, the selected five miRNAs (i.e. miR-215; $-532 ;-3619 ;-489$ and -130 a) found to influence breast cancer cell processes in the same fashion as does Pax-5. For example, 


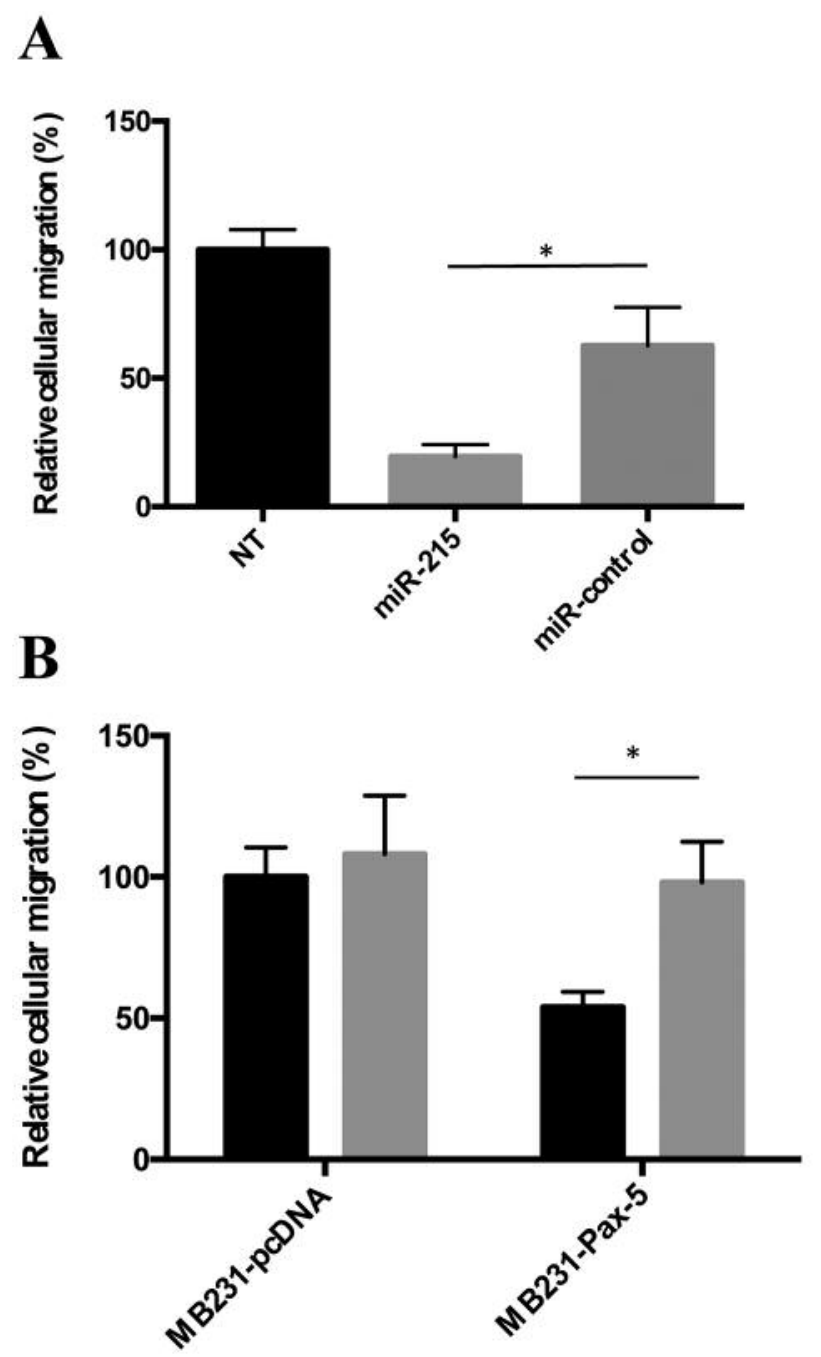

miR-130a, miR-489 and miR-215 have been found to be implicated in cell proliferation and invasion of breast cancer cells $(34,35)$ whereas miR-3619 and miR-532 have been shown to modulate these cancer processes in other types of solid tumors (36-39). Unfortunately, only miR-215 was validated in our breast cancer cell models conditionally overexpressing Pax-5.

Our analysis of TCGA database revealed that miR-215 expression is frequently down-regulated in tumor samples from breast cancer patients when compared to their healthy counterpart tissue. More specifically, in a cohort of 100 patients, 70 patients were found with attenuated levels of miR-215 in comparison to control tissues. These results are in agreement with previously published data indicating that low miR-215 expression in breast cancer tissue is associated with higher tumor grade and lymph node metastasis (32). Furthermore, a study from Madhavan et al., 2016 has reported that the levels of miR-215 in blood plasma from

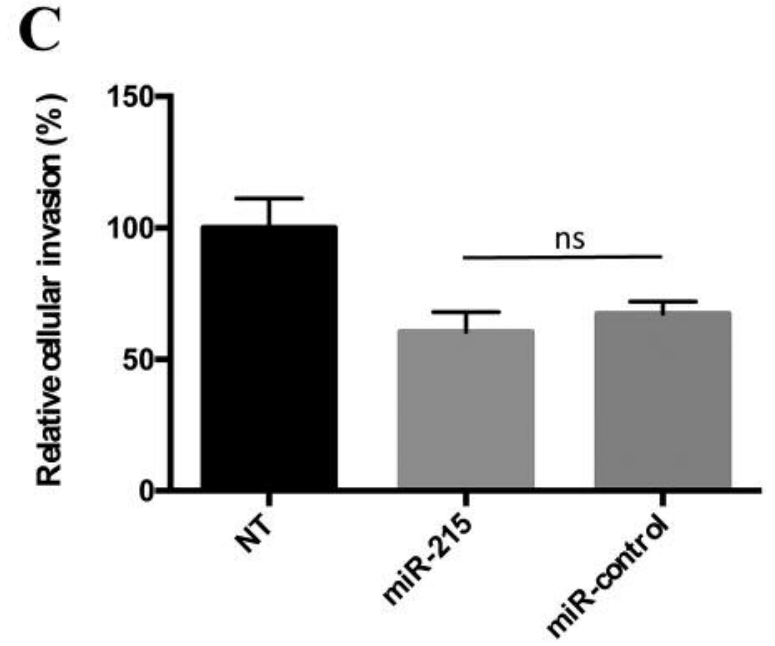

anti-control

anti-215

Figure 5. miR-215 inhibits cell migration. (A) Cell migration was monitored in MB231 cells transfected either with miR-215 mimics ( $\mathrm{miR}$ 215), transfected with scrambled non-targeting mimic (miR-control) or non-transfected (NT). (B) Cell migration was then performed on MB231-Pax-5 or MB231-pcDNA cells transfected with either an antimiR-215 (anti-215) or a scramble miRNA control (anti-control). Data are presented as means $\pm S E M$ of independent experimental triplicates $(* p<0.05)$.

breast cancer patients is a significant predictor of overall and progression-free survival (31). Altogether, these findings strongly suggest that miR-215 may act as a tumor suppressor and inhibitor of malignant breast cancer features. Furthermore, while we and others have characterized aberrant miR-215 expression in human breast tumors (40), Pax-5 transcription factor is identified as a potent regulator of miR-215 in breast cancer cells.

In our evaluation of miR-215 downstream targets, four mRNA-miRNA prediction tools were used and functional analysis was performed using the Kyoto Encyclopedia of genes and Genomes (KEGG) on 439 genes which were common and predicted by all four algorithms. Interestingly, amongst the top cellular signaling themes highlighted, "Pathways in cancer" and "MAPK signaling pathway" revealed a list of genes that have previously been associated to Pax-5 signaling in cancer cells $(2,13,15)$. Other functional terms such as "Neurotrophin signaling pathway", 

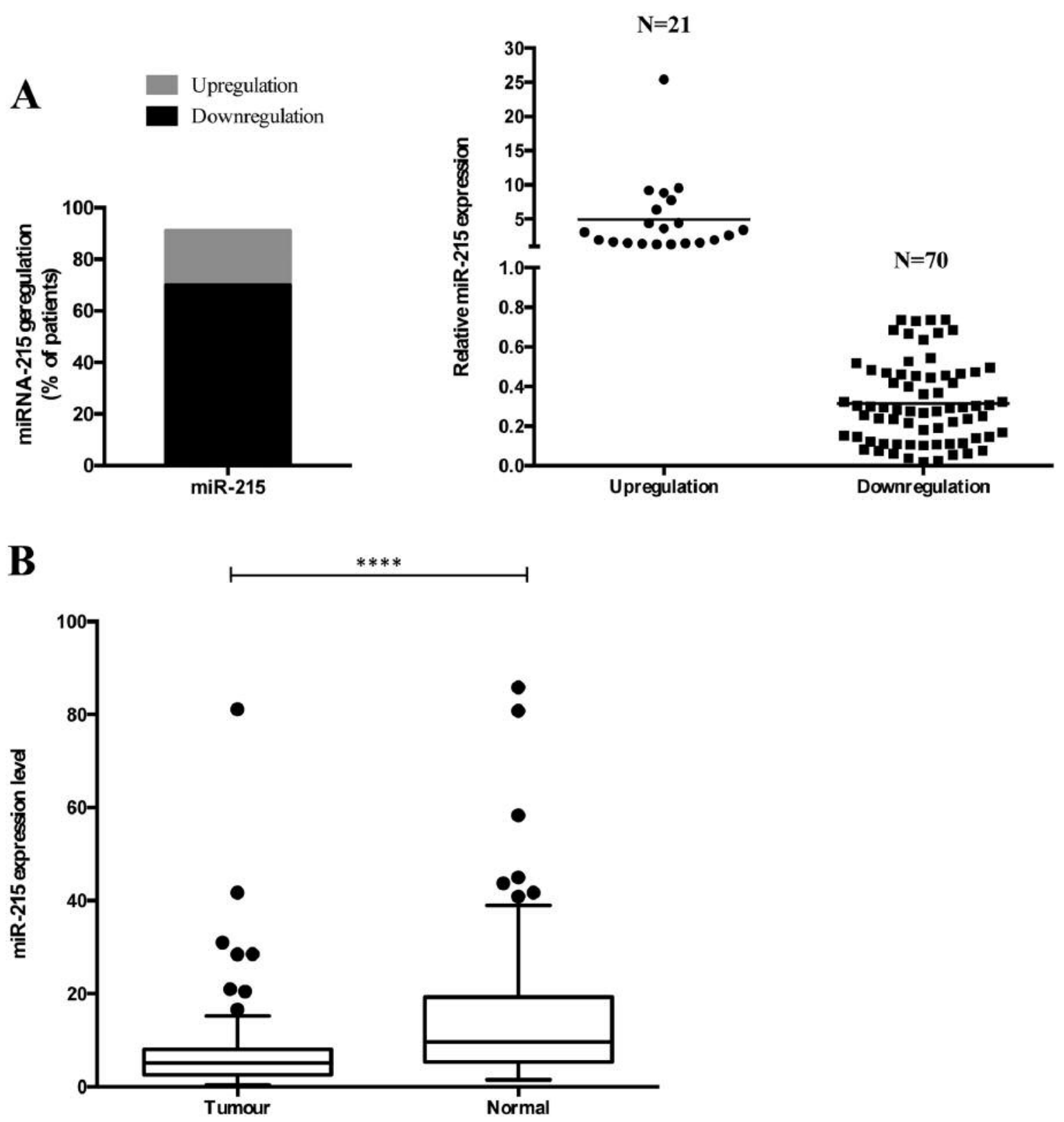

Figure 6. Clinical relevance of miR-215 in breast cancer patients. (A) MiRNA expression profiles from cancer tissues and marginal non-cancerous tissues were obtained from the breast cancer cohort through The Cancer Genome Atlas (TCGA) and plotted to display the percentage of patients presenting a 1.25-fold upregulation or downregulation of miR-215 in tumor tissue compared to healthy marginal tissue (left panel). The relative expression of miR-215 (tumor/healthy tissue) is plotted in all of 100 breast cancer patients (right). (B) Expression levels of miR-215 in tumour and non-tumour tissue (Normal) are shown by box blot. $(* * * * p<0.0001$, Wilcoxon test).

"Focal adhesion" and "Regulation of actin cytoskeleton" suggest the implication of miR-215 in morphological plasticity and cellular motility. Based on these analyses, several putative downstream transcriptional targets known for their involvement in cancer processes were selected and it was demonstrated that miR-215 negatively regulates the expression of ALCAM, CTNNBIP1, DICER1, DYRK3,
EREG, FNDC3B, and ZEB2 in breast cancer cells. Furthermore, given the capacity of Pax-5 to regulate miR215 , Pax-5 was shown to consequently inhibit transcription of the majority of these genes. These findings are consistent with the ability of Pax-5 to positively regulate miR-215.

It is important to note that most of the miR-215-targeted genes have oncogenic properties which corresponds to the 
tumor suppressive role of Pax-5 in breast cancer cells (4146). For example, Fibronectin type III domain containing 3B gene $(F N D C 3 B)$ located at the $3 \mathrm{q} 26$ locus is amplified in $20 \%$ of tumors and plays an oncogenic role in many cancers (41, 47). Additionally, activated leukocyte cell adhesion molecule (ALCAM) is implicated in cell to cell interactions and inhibits breast cancer apoptosis (43). ZEB2, a repressor of E-cadherin, has largely been characterized for its implication in EMT transitions and aggressivity in cancer $(42,48)$. Accordingly, we have also recently reported that Pax-5 is a potent inducer of E-cadherin and a concomitant inhibitor of ZEB expression in breast cancer cells leading to epithelial-dominant features (15). Indirectly, miR-215 may have a pivotal role in the pro-epithelialization processes mediated by Pax-5. Altogether, these findings align with the observations that miR-215 suppresses gene expression profiles governing pro-aggressive features in breast cancer. Consequently, miR-215 is also a potent downstream effector of the tumor suppressor activities of Pax-5 in breast cancer carcinogenesis.

Our study on the impact of miR-215 in malignant processes has shown that miR-215 is a strong regulator of breast cancer cell proliferation and migration activities. Accordingly, we demonstrate that miR-215 is critical effector for Pax-5-mediated suppression of these processes. These findings also corroborate with the genetic signatures and phenotypes highlighted in the KEGG analysis. Based on the literature, the ability of miR-215 to modulate these processes seems strongly dependant on cancer type. For example, miR215 has been identified to enhance migration and invasion in high-grade glioma by targeting retinoblastoma tumor suppressor gene 1 (49). On the other hand, miR-215 has been found to inhibit growth and cell invasion in epithelial ovarian cancer cells by targeting NOB1 (35). Since miRNAs target numerous genes, the cumulative effect of a miRNA will dictate its tumor suppressive or oncogenic role in that particular context. In our study, miR-215 was found to reduce proliferative and migratory capacities of breast cancer cells. More importantly, rescue experiments demonstrated that the reduction of cell migration and proliferation by Pax5 is dependant of miR-215 activity. Given that Pax-5 restoration in breast cancer cells is associated with proepithelialisation and up-regulation of the tumor-suppressive features of miR-215, strategies targeting the Pax-5/miR-215 axis may be used as potential therapeutic or diagnostic approaches in breast cancer patients. Surprisingly, although miR-215 inhibited MB231 cell migration, it did not alter the cells' invasive capacity. Given that cell migration and invasion processes are closely related by distinct activities, it may be possible that miR-215 targets a pivotal factor necessary for migration and is not related to cell invasion processes (ex: metalloproteinases). Further studies are warranted to elucidate these observations.
In summary, this study demonstrated that Pax-5 regulates numerous miRNAs including miR-215 which is aberrantly under-expressed in breast cancer tumors. Pax-5 found to inhibit aggressive features of breast cancer cells in a miR-215dependant manner. Restoration of this tumor-suppressive miRNA may represent a potential therapeutic approach against breast cancer malignancy and disease progression. Further studies are, thus, warranted to evaluate the therapeutic potential of miR-215 restoration in breast cancer.

\section{Conflicts of Interest}

None of the Authors have any conflicts of interest to disclose regarding this study.

\section{Acknowledgements}

The Authors gladly acknowledge the support by grants from the New Brunswick (NB) Innovation Foundation; the Canadian Breast Cancer Foundation; the Beatrice Hunter Cancer Research Institute; the Canadian Breast Cancer Society/QEII Foundation; and, the NB Health Research Foundation. Salaries for JH and NL are supported by the Beatrice Hunter Cancer Research Institute with funds provided by the Terry Fox Strategic Health Research Training Program in Cancer Research at CIHR in partnership with the NB Health Research Foundation.

\section{References}

1 Torre LA, Bray F, Siegel RL, Ferlay J, Lortet-Tieulent J and Jemal A: Global cancer statistics, 2012. CA Cancer J Clin 65: 87-108, 2015.

2 Vidal LJP, Perry JK, Vouyovitch CM, Pandey V, Brunet-Dunand SE, Mertani HC, Liu D-X and Lobie PE: PAX5alpha enhances the epithelial behavior of human mammary carcinoma cells. Mol Cancer Res 8: 444-456, 2010.

3 Kanteti R, Nallasura V, Loganathan S, Tretiakova M, Kroll T, Krishnaswamy S, Faoro L, Cagle P, Husain AN, Vokes EE, Lang $\mathrm{D}$ and Salgia R: PAX5 is expressed in small-cell lung cancer and positively regulates $\mathrm{c}-$ Met transcription. Laboratory Investigation 89: 301-314, 2009.

4 O'Brien P, Morin P, Ouellette RJ and Robichaud GA: The Pax5 Gene: A Pluripotent Regulator of B-cell Differentiation and Cancer Disease. Cancer Res 71: 7345-7350, 2011.

5 Robson EJD, He S-J and Eccles MR: A PANorama of PAX genes in cancer and development. Nat Rev Cancer 6: 52-62, 2006.

6 Strachan T and Read AP: PAX genes. Curr Opin Genet Dev 4: 427-438, 1994.

7 Adams B, Dörfler P, Aguzzi A, Kozmik Z, Urbánek P, MaurerFogy I and Busslinger M: Pax-5 encodes the transcription factor BSAP and is expressed in B lymphocytes, the developing CNS, and adult testis. Genes Development 6: 1589-1607, 1992.

8 Hagman J, Wheat W, Fitzsimmons D, Hodsdon W, Negri J and Dizon F: Pax-5/BSAP: regulator of specific gene expression and differentiation in B lymphocytes. In: Signal transduction and the coordination of $b$ lymphocyte development and function $i$ : transduction of ber signals from the cell membrane to the nucleus. Justement LB and Siminovitch KA (eds.). Berlin, Heidelberg: Springer Berlin Heidelberg, pp. 169-194, 2000. 
9 Rolink AG, Schaniel C, Busslinger M, Nutt SL and Melchers F: Fidelity and infidelity in commitment to B-lymphocyte lineage development. Immunol Rev 175: 104-111, 2000.

10 Robichaud GA, Nardini M, Laflamme M, Cuperlovic-Culf M and Ouellette RJ: Human Pax-5 C-terminal isoforms possess distinct transactivation properties and are differentially modulated in normal and malignant B cells. J Biol Chem 279: 49956-49963, 2004.

11 Robichaud GA, Perreault JP and Ouellette RJ: Development of an isoform-specific gene suppression system: the study of the human Pax-5B transcriptional element. Nucl Ac Res 36: 46094620, 2008.

12 Krenacs L, Himmelmann AW, Quintanilla-Martinez L, Fest T, Riva A, Wellmann A, Bagdi E, Kehrl JH, Jaffe ES and Raffeld M: Transcription factor B-cell-specific activator protein (BSAP) is differentially expressed in B cells and in subsets of B-cell lymphomas. Blood 92: 1308-1316, 1998.

13 Liu W, Li X, Chu ESH, Go MYY, Xu L, Zhao G, Li L, Dai N, Si J, Tao Q, Sung JJY and Yu J: Paired box gene 5 is a novel tumor suppressor in hepatocellular carcinoma through interaction with p53 signaling pathway. Hepatology 53: 843-853, 2011.

14 Benzina S, Harquail J, Guerrette R, O’Brien P, Jean S, Crapoulet $\mathrm{N}$ and Robichaud GA: Breast cancer malignant processes are regulated by Pax -5 through the disruption of FAK signaling pathways. J Cancer 7: 2035-2044, 2016.

15 Benzina S, Beauregard A-P, Guerrette R, Jean S, Daro Faye M, Laflamme M, Maïcas E, Crapoulet N, Ouellette RJ and Robichaud GA: Pax-5 is a potent regulator of E-cadherin and breast cancer malignant processes. Oncotarget 8: 12052-12066, 2017.

16 Vouyovitch CM, Vidal L, Borges S, Raccurt M, Arnould C, Chiesa J, Lobie PE, Lachuer J and Mertani HC: Proteomic analysis of autocrine/paracrine effects of human growth hormone in human mammary carcinoma cells. Adv Exp Med Biol 617: 493-500, 2008.

17 Schebesta A, McManus S, Salvagiotto G, Delogu A, Busslinger GA and Busslinger M: Transcription factor Pax 5 activates the chromatin of key genes involved in b cell signaling, adhesion, migration, and immune function. Immunity 27: 49-63, 2007.

18 Huang Y, Shen XJ, Zou Q, Wang SP, Tang SM and Zhang GZ: Biological functions of microRNAs: a review. J Physiol Biochem 67: 129-139, 2011

19 Macfarlane L-A and Murphy PR: MicroRNA: Biogenesis, function and role in cancer. Curr Genomics 11: 537-561, 2010.

20 Bartel DP: MicroRNAs: target recognition and regulatory functions. Cell 136: 215-233, 2009.

21 Shenouda SK and Alahari SK: MicroRNA function in cancer: oncogene or a tumor suppressor? Cancer Metastasis Rev 28: 369-378, 2009.

22 Iorio MV and Croce CM: MicroRNAs in cancer: small molecules with a huge impact. J Clin Oncol 27: 5848-5856, 2009.

23 Harquail J, Benzina S and Robichaud GA: MicroRNAs and breast cancer malignancy: an overview of miRNA-regulated cancer processes leading to metastasis. Cancer Biomark 11: 269280, 2012.

24 Garzon R, Calin GA and Croce CM: MicroRNAs in Cancer. Annu Rev Med 60: 167-179, 2009.

25 Corney DC, Flesken-Nikitin A, Godwin AK, Wang W and Nikitin AY: MicroRNA-34b and MicroRNA-34c are targets of p53 and cooperate in control of cell proliferation and adhesionindependent growth. Cancer Research 67: 8433-8438, 2007.
26 O’Donnell KA, Wentzel EA, Zeller KI, Dang CV and Mendell JT: c-Myc-regulated microRNAs modulate E2F1 expression. Nature 435: 839-843, 2005.

27 Bracken CP, Gregory PA, Kolesnikoff N, Bert AG, Wang J, Shannon MF and Goodall GJ: A double-negative feedback loop between ZEB1-SIP1 and the microRNA-200 family regulates epithelialmesenchymal transition. Cancer Res 68: 7846-7854, 2008.

28 Livak KJ and Schmittgen TD: Analysis of relative gene expression data using real-time quantitative PCR and the 2(Delta Delta C(T)) Method. Methods 25: 402-408, 2001.

29 Picot N, Guerrette R, Beauregard A-P, Jean S, Michaud P, Harquail J, Benzina $S$ and Robichaud GA: Mammaglobin 1 promotes breast cancer malignancy and confers sensitivity to anticancer drugs. Molec Carcin 55: 1150-1162, 2016.

30 Cormier K, Harquail J, Ouellette RJ, Tessier PA, Guerrette R and Robichaud GA: Intracellular expression of inflammatory proteins S100A8 and S100A9 leads to epithelial-mesenchymal transition and attenuated aggressivity of breast cancer cells. Anticancer Agents Med Chem 14: 35-45, 2014.

31 Madhavan D, Peng C, Wallwiener M, Zucknick M, Nees J, Schott S, Rudolph A, Riethdorf S, Trumpp A, Pantel K, Sohn C, ChangClaude J, Schneeweiss A and Burwinkel B: Circulating miRNAs with prognostic value in metastatic breast cancer and for early detection of metastasis. Carcinogenesis 37: 461-470, 2016.

32 Zhou SW, Su BB, Zhou Y, Feng YQ, Guo Y, Wang YX, Qi P and $\mathrm{Xu}$ S: Aberrant miR-215 expression is associated with clinical outcome in breast cancer patients. Med Oncol 31: 259, 2014.

33 Huang DW, Sherman BT, Tan Q, Collins JR, Alvord WG, Roayaei J, Stephens R, Baseler MW, Lane HC and Lempicki RA: The DAVID Gene Functional Classification Tool: a novel biological module-centric algorithm to functionally analyze large gene lists. Genome Biol 8: R183, 2007.

34 Yao J, Zhang P, Li J and Xu W: MicroRNA-215 acts as a tumor suppressor in breast cancer by targeting AKT serine/threonine kinase 1. Oncol Lett 14: 1097-1104, 2017.

35 Lin Y, Jin Y, Xu T, Zhou S and Cui M: MicroRNA-215 targets NOB 1 and inhibits growth and invasion of epithelial ovarian cancer. Am J Transl Res 9: 466-477, 2017.

36 Liu GJ, Cimmino L, Jude JG, Hu Y, Witkowski MT, McKenzie MD, Kartal-Kaess M, Best SA, Tuohey L, Liao Y, Shi W, Mullighan CG, Farrar MA, Nutt SL, Smyth GK, Zuber J and Dickins RA: Pax5 loss imposes a reversible differentiation block in B-progenitor acute lymphoblastic leukemia. Genes Development 28: 1337-1350, 2014.

37 Niu X, Liu S, Jia L and Chen J: Role of MiR-3619-5p in bCatenin-Mediated Non-Small Cell Lung Cancer Growth and Invasion. Cell Physiol Biochem 37: 1527-1536, 2015.

$38 \mathrm{Hu} \mathrm{S}$, Zheng Q, Wu H, Wang C, Liu T and Zhou W: miR-532 promoted gastric cancer migration and invasion by targeting NKD1. Life Sci 177: 15-19, 2017.

39 Bai L, Wang H, Wang AH, Zhang LY and Bai J: MicroRNA-532 and microRNA-3064 inhibit cell proliferation and invasion by acting as direct regulators of human telomerase reverse transcriptase in ovarian cancer. PLOS ONE 12: e0173912, 2017.

40 van Schooneveld E, Wouters MCA, Van der Auwera I, Peeters DJ, Wildiers H, Van Dam PA, Vergote I, Vermeulen PB, Dirix LY and Van Laere SJ: Expression profiling of cancerous and normal breast tissues identifies microRNAs that are differentially expressed in serum from patients with (metastatic) breast cancer and healthy volunteers. Breast Cancer Res 14: R34, 2012. 
41 Cai C, Rajaram M, Zhou X, Liu Q, Marchica J, Li J and Powers RS: Activation of multiple cancer pathways and tumor maintenance function of the $3 \mathrm{q}$ amplified oncogene FNDC3B. Cell Cycle 11: 1773-1781, 2012.

42 Qiao Y, Shiue CN, Zhu J, Zhuang T, Jonsson P, Wright APH, Zhao $\mathrm{C}$ and Dahlman-Wright K: AP-1-mediated chromatin looping regulates ZEB2 transcription: new insights into TNF- $\alpha-$ induced epithelial-mesenchymal transition in triple-negative breast cancer. Oncotarget 6: 7804-7814, 2015.

43 Jezierska A, Matysiak W and Motyl T: ALCAM/CD166 protects breast cancer cells against apoptosis and autophagy. Med Sci Monit 12: BR263-273, 2006.

44 Farooqui M, Bohrer LR, Brady NJ, Chuntova P, Kemp SE, Wardwell CT, Nelson AC and Schwertfeger KL: Epiregulin contributes to breast tumorigenesis through regulating matrix metalloproteinase 1 and promoting cell survival. Molecular Cancer 14: 138, 2015.

45 Mukherjee N, Dasgupta H, Bhattacharya R, Pal D, Roy R, Islam S, Alam N, Biswas J, Roy A, Roychoudhury S and Panda CK: Frequent inactivation of MCC/CTNNBIP1 and overexpression of phospho-beta-catenin Y654 are associated with breast carcinoma: Clinical and prognostic significance. BBA-Molec Basis of Disease 1862: 1472-1484, 2016.
46 Karube $\mathrm{Y}$, Tanaka H, Osada H, Tomida S, Tatematsu Y, Yanagisawa K, Yatabe Y, Takamizawa J, Miyoshi S, Mitsudomi $\mathrm{T}$ and Takahashi T: Reduced expression of Dicer associated with poor prognosis in lung cancer patients. Cancer Sci 96: 111-115, 2005.

47 Lin $\mathrm{CH}$, Lin YW, Chen YC, Liao CC, Jou YS, Hsu M-T and Chen CF: FNDC3B promotes cell migration and tumor metastasis in hepatocellular carcinoma. Oncotarget 7: 4949849508, 2014.

48 Thiery JP, Acloque H, Huang RYJ and Nieto MA: EpithelialMesenchymal Transitions in Development and Disease. Cell 139: 871-890, 2009.

49 Wei Y, Sun J and Li X: MicroRNA-215 enhances invasion and migration by targeting retinoblastoma tumor suppressor gene 1 in high-grade glioma. Biotechnol Lett 39: 197-205, 2017.

Received June 20, 2018

Revised July 18, 2018

Accepted July 23, 2018 